stein has been unable to ascribe reversion to the loss of any particular human chromosome or chromosomes but believes that not more than two are involved.

The principal problem in synaptogenesis is not its raison d'être but its mechanism-how do innervating fibres recognise their target cells, how specific is that recognition and what part is played by competitive interactions between innervating fibres? C. Sotelo (INSERM) reviewed morphological evidence from mouse cerebellar mutants that in the absence of the normal postsynaptic sites, growing nerve fibres will make alternative synapses and conversely that in the absence of their normal innervation postsynaptic structures can attract nerve fibres which would not normally reach them.

The existence of relatively nonspecific specialised sites intrinsic to the membrane of postsynaptic cells in the CNS was emphasised by G. Raisman (MRC Mill Hill) who described the reinnervation of denervated adult rat superior cervical ganglion cells by the vagus and the hypoglossal nerves at the sites of the postsynaptic thickenings originally occupied by preganglionic nerve fibres.

The molecular nature of the recognition system for postsynaptic membrane is unknown, although one obvious possibility is the neurotransmitter receptors themselves. Most attempts to test that possibility in the central nervous system have failed. But J. Freeman (Vanderbilt University) has succeeded in showing that the retinotectal system in Bufo is cholinergic, and claims that by applying the cholinergic receptor blocker $\alpha$-bungarotoxin to small areas of the developing optic tectum he can create localised defects in the electrophysiological map of the visuo-tectal projection.

Detailed studies on the behaviour of receptors are much easier at the neuromuscular junction, where it is believed that the increased density of receptors at the postsynaptic membrane is a consequence of innervation rather than its cause. G. Fischbach (Harvard University) however presented evidence that chick skeletal muscle cells in vitro develop areas of high receptor concentration in the absence of innervation. These receptor "hot spots" are detected by intracellular recordings from the muscle as areas of heightened sensitivity to focal stimulation with $\mathrm{ACh}$, which confirms Nirenberg's report that local concentrations of $\alpha$-bungarotoxin receptor binding sites exist on muscle cells in vitro.

The stability of concentrations of receptor sites in vivo was emphasised by C. Slater (Newcastle General Hospital), who finds that the peaks of sensitivity that develop in denervated adult rat soleus on reinnervation with the superficial fibular nerve persist for at least a week after section of the fibular nerve.

The question of competitive interactions in the specification of neuromuscular junctions formed in developing mammals was addressed by $D$. van Essen (University College London), who reported that the multiple innervation found in neonatal soleus is eliminated by $2-3$ weeks after birth, through the withdrawal of supernumerary terminals by the motor axons. This shrinkage occurs however even when half the competing terminals are removed by the early section of one of the ventral roots, and some muscle fibres are left vacant. In experiments in which an immature muscle was denervated and reinnervated by a foreign nerve which was then forced to compete for synaptic sites with the regenerating terminals of the original nerve, multiple innervation persisted only where the synapses were at least $1 \mathrm{~mm}$ apart.

The resolution of problems in synaptogenesis seems likely to be found in the properties of the membranes; the properties of gap junctions will remain a series of tantalising hints until someone can define a disruptive effect of blocking them in vivo.

\section{Radiological data collection}

\section{from a Correspondent}

A meeting on Radiological Protection Data: Collection, Recording and Use, organised by the Society for Radiological Protection was held in London on April 6, 1976.

A NATIONAL register of radiation workers is to be set up in this country, S. Rae, Assistant Director (Medical) of the National Radiological Protection Board, told the meeting. Negotiations for establishing the register, initially to cover workers in the nuclear energy industry, are now being conducted. It is hoped to extend it to include for example, industrial radiographers and miners exposed to radiation.

The purpose of setting up such a national register will be to carry out an epidemiological study of cancer mortality in radiation workers and to look for effects of occupational radiation exposure on the natural rate of cancer induction. The register will follow, for at least 25 years, the radiation exposure of a large population of radiation workers and will match this with information obtained from the records of the Office of Population Censuses and
Surveys about the age at death and the cause of death of these workers.

$\mathrm{He}$ indicated that calculations, based on current estimates of rates of cancer induction per million individuals per rad, suggest that even with a postulated study of 10,000 workers followed for 25 years it is most unlikely that there would be a detectable increase in the number of cancer deaths from occupational exposure to radiation at the currently existing level. If, however, no excess mortality is demonstrated by such a study then we can conclude that the risk coefficients we assume and the levels of radiation exposure we endeavour to keep to are justified, and this information is well worth knowing.

R. H. Clarke (Berkeley Nuclear Laboratories) described some work he had been carrying out in conjunction with Professor Mayneord on computer modelling of non-linear dose-response relationships. He quoted considerable published evidence for a non-linear, peaked, response between dose and risk and then discussed the implications of such a relationship in radiological protection. From his studies, Clarke was unable to show that the absolute expectations of malignant conditions were significantly greater for these non-linear dose-response functions than for the conventional linear hypothesis on which the recommendations of the International Commission on Radiological Protection are based.

The familiar film-badge which radiation workers have been used to wearing for so many years in this country will for many of them soon become a thing of the past. The National Radiological Protection Board is shortly to introduce a new themoluminescent dosemeter (TLD) for the majority of its customers and a prototype of the dosemeter was on display for the first time at the meeting. The dosemeter consists of a metal plate carrying two inserts of lithium fluoride-impregnated PTFE discs. The dosemeter is wrapped in black polythene film and worn in a black plastic holder.

The advantage of a TLD is that it readily lends itself to automation in dosemeter issue and readout, and in dose record keeping. E. Greenslade (NRPB) told the meeting about the relatively simple interim dose record keeping service, based on film-badges, at present operated by the NRPB. This service covers some 3,800 workers at 330 establishments. The new TLD will form the basis of an automated dosemeter issue and record keeping service which will be capable of holding up to 200,000 records. L. Salmon (Atomic Energy Research Establishment, Harwell) described the data base system, DIRK, which had been developed at Harwell for the NRPB's automated TLD service. 